\title{
The Role of State Programs in the Innovative Development of Russia
}

\author{
Victoria Kookueva \\ Department of Economic Innovation and Finance \\ Plekhanov Russian University of Economics \\ Moscow Russia \\ kookueva.vv@gmail.com
}

\begin{abstract}
This research paper analyzes the main issues of the efficiency of Russia Federation financing of innovative development of the country's economy. Country's involvement and co-financing in various aspects of economic development is typical for Russian practice, including in the field of innovative development. There are advantages and disadvantages in public and private financing of innovation and innovation development. On the one hand, with private financing, the effectiveness is usually higher because the investor controls and monitors his investments and is not interested in ineffective project financing. On the other hand, the private sector carefully selects the direction of its investments, so consequently projects with low growth potential and with high risks may not be interesting. In addition, private investors do not undertake large projects without the participation of the state. As for the regional level, the system of inter-budgetary relations in Russia is created in such a way that only a few regions have sufficient financial resources of their own. In most cases, regions are subsidized with insufficient funds even for current expenses, especially for capital. Therefore, social, economic, as well as innovative progress of the country is not possible without government funding. This research paperwork analyzes the system of state programs in the main areas, paying special attention to the field of Innovative Development and Modernization of the Economy. The performed correlation-regression analysis showed, on the one hand, a positive relationship between the amount of budget funds spent and GDP, on the other hand, when analyzing the impact of individual programs on indicators, the relationship and dependence became much weaker. Despite the ambiguity of the results gained, we believe that the state should unquestionably contribute in the innovative development of the country. The state should not only finance expenses, but also stimulate development from the private sector and should also ensure high efficiency of public funds.
\end{abstract}

Keywords-innovative development, government support, financing, government programs.

\section{INTRODUCTION}

Innovative development is an important factor for expanded reproduction, a driver of economic growth, which is necessary to start the process of innovative development of economy. It is discussable whether the instruments of state incentives can be such drivers. Nevertheless, there is no doubt that the development of the innovation system is impossible without state support. About 10 years ago, an emphasis was placed on strategic planning, which presupposes the implementation of development programs for the medium term. The advantages of medium-term plans are that there is a gradual implementation of the program in action, the processes are interconnected, and funding is distributed according to plans and activities. Despite this, there are problems associated with financing and the efficiency of the costs incurred. Therefore, already now it is possible to summarize the results of the implementation of individual programs, and highlight such problems as insufficient funding, disruption of the financing plan and, accordingly, the inability to achieve certain targets by the previously indicated date. It can also be concluded that there are incorrect indicators and target indicators of state programs that do not characterize the specificity of the program, do not have a direct strong connection and dependence. The main problem is the financial provision of all programs and to improve the efficiency of use.

The purpose of this research paperwork is to study the role of government programs in innovative development.

\section{METHODS}

Evaluation of government programs raises efficiency issues based on the achievement of targets and indicators. There are contradictory approaches regarding their efficiency and appropriateness. Government programs are associated as a tool for implementing the concept of performance-based budgeting [1]. Some scholars believe that government programs copy federal targeted programs and are not a tool for modernizing the economy, and are exposed to the risks of underfunding. But the federal targeted programs were not adapted to the type of the federal budget program, which required their transfer to state programs. The latter 
have evolved from a strategic planning tool into a cost management tool [2].

The object of research of various Russian and foreign scientists has often been an assessment of the impact of budgetary spending on economic growth and economic development. According to Keynes, government regulation is very important, and government spending affects the economy with a multiplier. In addition to this, it is believed that the state is influenced through the tax system. There is also a contrary opinion, according to which the budgetary expenditures are insignificant in the long term. Russian scientist believe as well that the provision of substantial budgetary funds above the required level gives a negative effect. The important thing here is the effectiveness of the provision of budget funds, rather than their amount [3]. According to F. S. Forte and S. Magazino [4] state share costs to GDP must be at $37 \%$ of GDP, and according to V. Yllarionova, N. Pyvovarova - from 15 to $24 \%$ [5]. A. A. Batista, E. M. Ribeiro, N.M. Gomes, N. M., \& A. N. Paula believe that projects tied to a certain territory have a high probability of a positive result, but at the same time, there is the risks of ineffective management [6]. There are also studies that reveal the relationship between state support and the development of entrepreneurship [11], the importance of small and medium-sized businesses in the development of the country's economy [12]. The development of entrepreneurship is not sufficiently developed, which indicates a small impact on the level of economic development in developing countries [13]. The lack of innovative companies, technological start-ups [14], insufficient financing of small and medium-sized businesses [15], and individual territories [16] hinder the development of the economy, the country, and its regions.

Various research methods have been used during the research process. To substantiate the theoretical part of the study, various methods of theoretical knowledge were applied, the discussable subject of the study was proved. As empirical research methods, economic and statistical research methods were used, including the correlation-regression method, correlation, comparative analysis and others.

\section{MAIN PART}

One of the most important tool is State programs that have replaced federal targeted programs. Now State programs have gotten through the system of national projects. The system of State programs roots down to 2011, which gradually increased the program part of the federal budget. As can be seen from the figure 1 the program part of the federal budget by 2019 amounted to more than $75 \%$ of all federal budget expenditures.

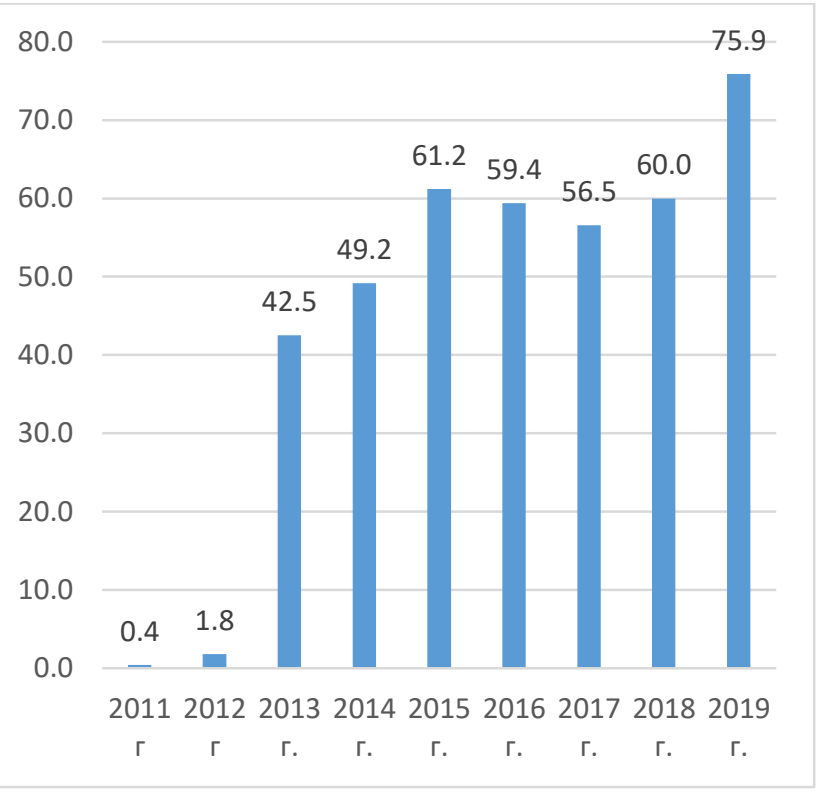

Fig.1. The share of the program part in the structure of federal budget expenditures in 2011-2019, \% (compiled on the basis of data from the Ministry of Finance of the Russian Federation)

Since 2011, State programs have begun in the direction of "New Quality of Life," in particular the program "Social Support for Citizens." Figures 2 and 3, Table 1 shows that major portion of expenditures of the program federal budget fall on the "New Quality of Life," which includes programs aimed at supporting citizens, developing the transport system, education, health care, culture, providing affordable housing and others.

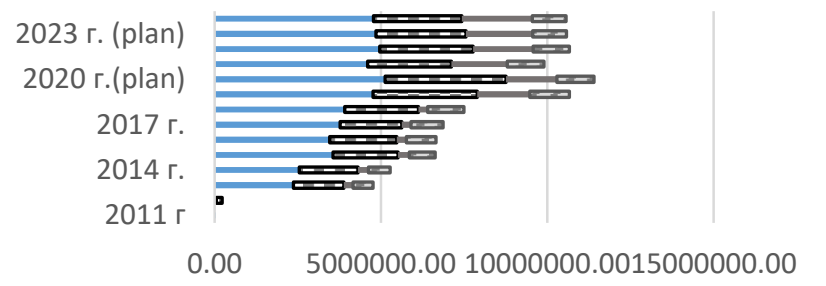

A New living standards

QInnovation-driven growth and modernization of the economy

An effective State

Fig.2. Dynamics of financing of State programs in the main areas, million rubles.

In 2012, programs were introduced in the direction of "Innovative development and modernization of the economy," which has a wide range: from science and technology to the reproduction of natural resources. State programmes in the areas of "Effective State" and "Balanced Regional Development" have less funding than previously mentioned programmes, but their share is significantly increasing in the coming years. The direction "Effective State" is aimed at improving the system of public finances, justice, financial markets, and state property management. Balanced regional development in general is aimed at the 
development of the Far East, Crimea, the North Caucasus, the Arctic zone and, in general, at improving federal relations.

\begin{tabular}{|l|c|c|c|c|}
\hline & $\begin{array}{c}\text { New } \\
\text { quality of } \\
\text { life }\end{array}$ & $\begin{array}{c}\text { Innovative } \\
\text { development and } \\
\text { modernization of } \\
\text { the economy }\end{array}$ & $\begin{array}{c}\text { Effective } \\
\text { state }\end{array}$ & $\begin{array}{c}\text { Balanced } \\
\text { regional } \\
\text { development }\end{array}$ \\
\hline 2011 vear & 100 & 0 & 0 & 0 \\
\hline 2012 vear & 24.7 & 75.3 & 0.0 & 0.0 \\
\hline 2013 year & 41.9 & 26.7 & 4.7 & 10.6 \\
\hline 2014 vear & 41.2 & 28.3 & 5.0 & 10.6 \\
\hline 2015 vear & 46.1 & 25.3 & 4,3 & 10.0 \\
\hline 2016 vear & 45.4 & 26.3 & 3.8 & 11.7 \\
\hline 2017 year & 49.2 & 24.2 & 3.5 & 12.6 \\
\hline 2018 vear & 46.9 & 26.4 & 3.4 & 13.0 \\
\hline 2019 vear & 41.3 & 27.1 & 13,7 & 10.3 \\
\hline 2020 vear (plan) & 41.6 & 29.4 & 12.4 & 9.0 \\
\hline 2021 year (plan) & 42.5 & 23.1 & 15.5 & 10.2 \\
\hline 2022 vear (plan) & 42.7 & 24.1 & 15.5 & 9.4 \\
\hline 2023 vear (plan) & 42.0 & 23.3 & 17.4 & 8.8 \\
\hline 2024 year (plan) & 41.3 & 22.9 & 18.3 & 8.7 \\
\hline
\end{tabular}

Fig.3. Share OF the STATE Programs of THE FEDERAL BUdGET IN MAIN AREAS, \%

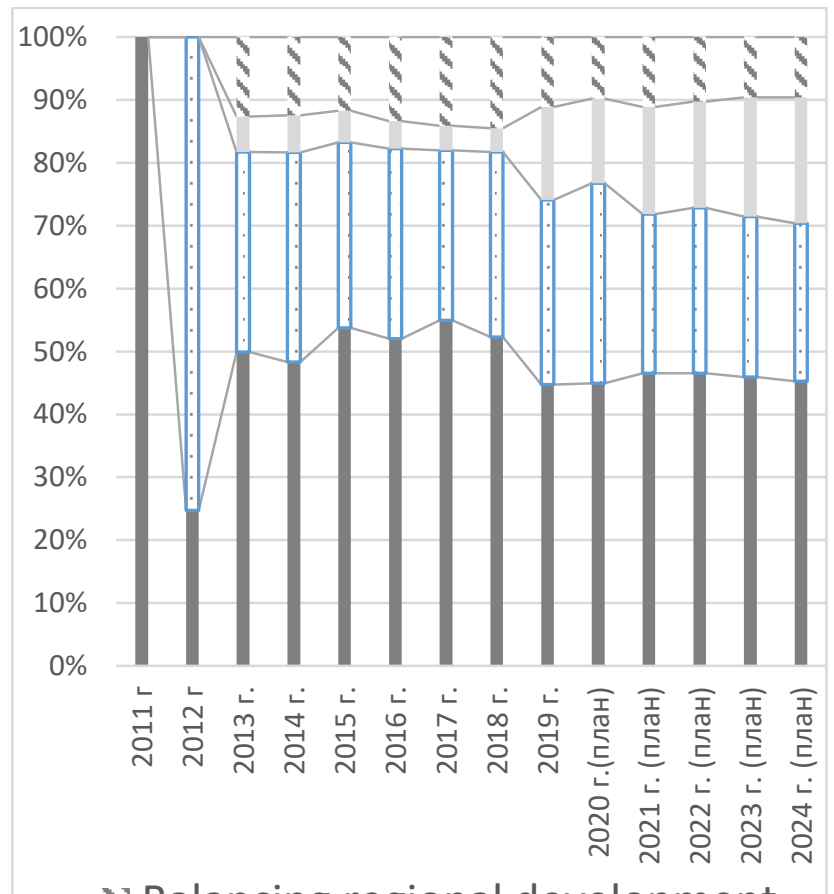

$\aleph$ Balancing regional development

Fig.4. Share of state programs of the federal budget in the main areas,

As part of this study, we will consider state programs in the direction of "Innovative development and modernization of the economy." It should be noted that part of the state programs has already ceased to exist, part has been transformed into other programs, and part of the programs has become a category of national projects. In general, state programs of innovative development affect important sectors and areas of development, in particular, the development of energy, space, technology, agriculture, forestry, the nuclear industry, pharmaceuticals, radio electronics, and shipbuilding. There are also programs without reference to any particular industry, but to the innovative development of the country as a whole.

An analysis of the dynamics of financing of government programs since 2013 showed that most of the budget funds were spent on the development of the transport system, while the amount of allocated funds increased every year - from 713.78 billion rubles in 2013 to 979.2 billion rubles in 2019 , which is in total for 2013-2019 - more than 5.8 trillion rubles. Picture 4. shows the structure of expenditures allocated for the implementation of government programs, where the amount of funding was taken into account in total for 20132019. It can be seen on the picture that the largest amount of funds was allocated for the "Development of the transport system" program, which is more than $37 \%$.

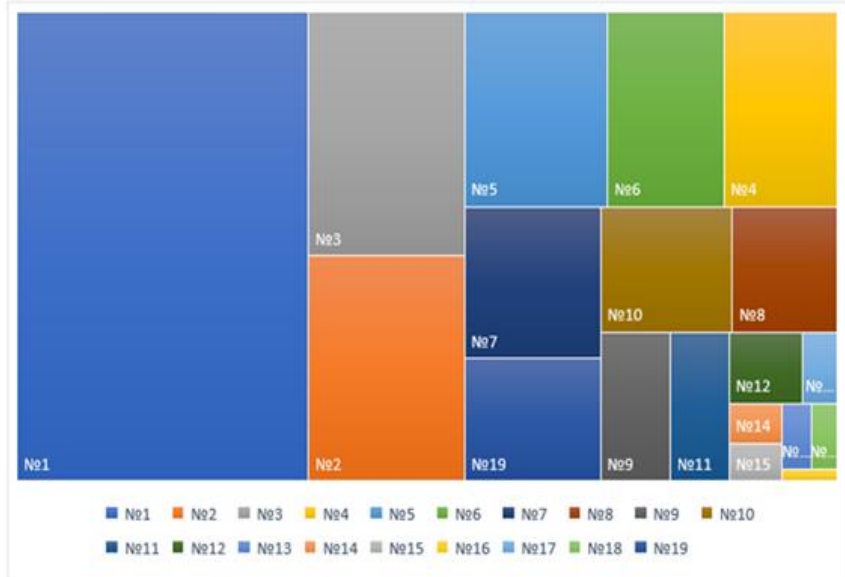

Fig.5. The structure of financing of state programs in the field of Innovative Development and Modernization of the Economy for the period from 2013-2019

* - No. 1- Development of the transport system, No. 2Development of industry and increasing its competitiveness, No. 3- Development of agriculture and regulation of markets for agricultural products, raw materials and food, No. 4 Development of science and technology, No. 5 - Space activities of Russia, No. 6- Information society, No. 7 Economic development and innovative economy, No. 8 Development of foreign economic activity, No. 9Development of the aviation industry, No. 10 - Development of the nuclear power-industrial complex, No. 11Reproduction and use of natural resources, No. 12Development forestry, No. 13 - Development of the fishery complex, No. 14- Energy development, No. 15-Development of the electronic and radio-electronic industry, No. 16Development of the military-industrial complex, No. 17Development of shipbuilding and equipment for the development of shelf deposits, No. 18 - Development pharmaceutical and medical industry, No. 19 - Scientific and technological development of the Russian Federation.

We have conducted a correlation analysis of the relationship between the costs of the transport system development program and the volume of GDP. The obtained correlation coefficient of 0.8 shows a close direct relationship between them. However, the obtained correlation-regression 
analysis did not show a high connection and dependence between these indicators.

$$
\begin{aligned}
& y=144.52 x-30564 \\
& R^{2}=0.6395
\end{aligned}
$$

The results are shown in the Picture 5. It can be seen that the model describes only $64 \%$ of observations. Only the financing of the development of the transport system does not cause the growth of GDP from the federal budget.

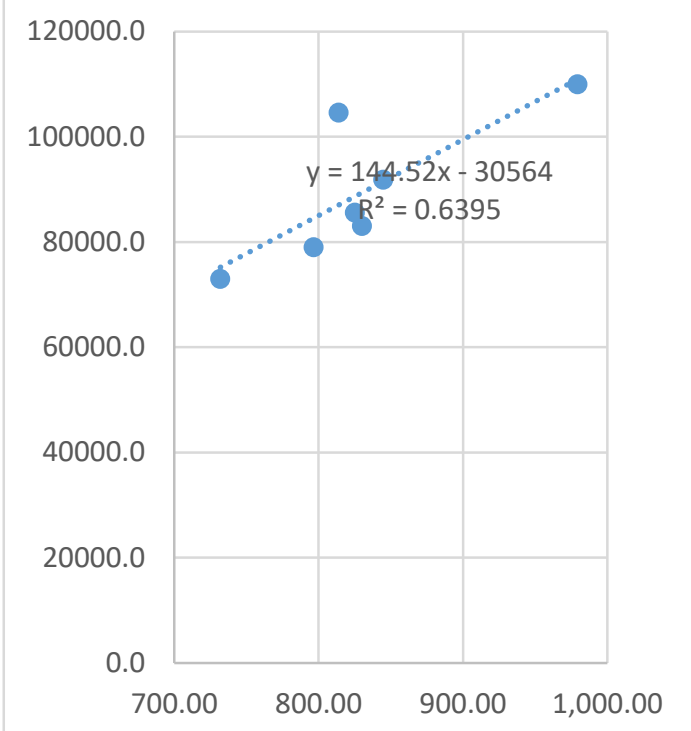

Fig.6. Correlation-regression analysis of the dependence of GDP on the amount of financing of the state enterprise Development of the Transport System

We will analyze whether there is a connection and dependence between the amount of funding for the same state program and such an indicator as the share of public roads that meet the requirements. Correlation analysis showed a direct strong relationship (0.71). However, the correlationregression analysis showed that there is a relationship between them, but the model shows that the $51 \%$ increase in the share of roads is due to the volume of financing of the specified state program.

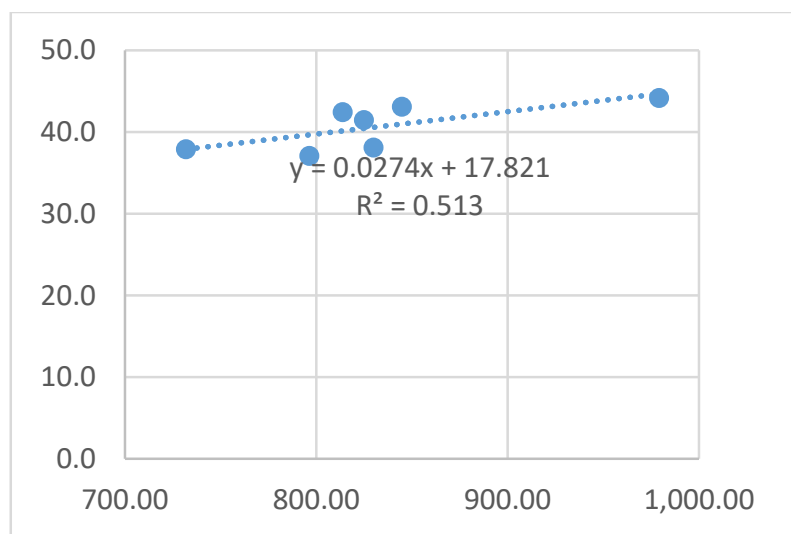

Fig.7. Correlation-regression analysis of the dependence of the shares and public roads that meet the requirements on the amount of financing of the state enterprise Development of the Transport System
Unfortunately, due to the lack of information on the achievement of the key target parameters of the implementation of the state enterprise Development of the Transport System, it is not possible to identify the connection and prove that the implementation of this program influenced the improvement of indicators characterizing the development of the transport system.

Also significant in terms of funding are programs aimed at developing industry and increasing its competitiveness, as well as at developing agriculture. In total, they make up about $20 \%$ of the total volume of innovative development programs. Picture 7 shows that the first three programs in terms of funding amount to $55 \%$ of all allocated funds in this area, the first 7 programs $-83 \%$, the remaining 11 programs make up $17 \%$ of funds. Hence, we can conclude that the policy of state support for innovative development is reduced to industrial policy as a whole. Most of all funds in this field are spent on the development of the transport system, agriculture, industry, but programs that are innovative, have much less funding.
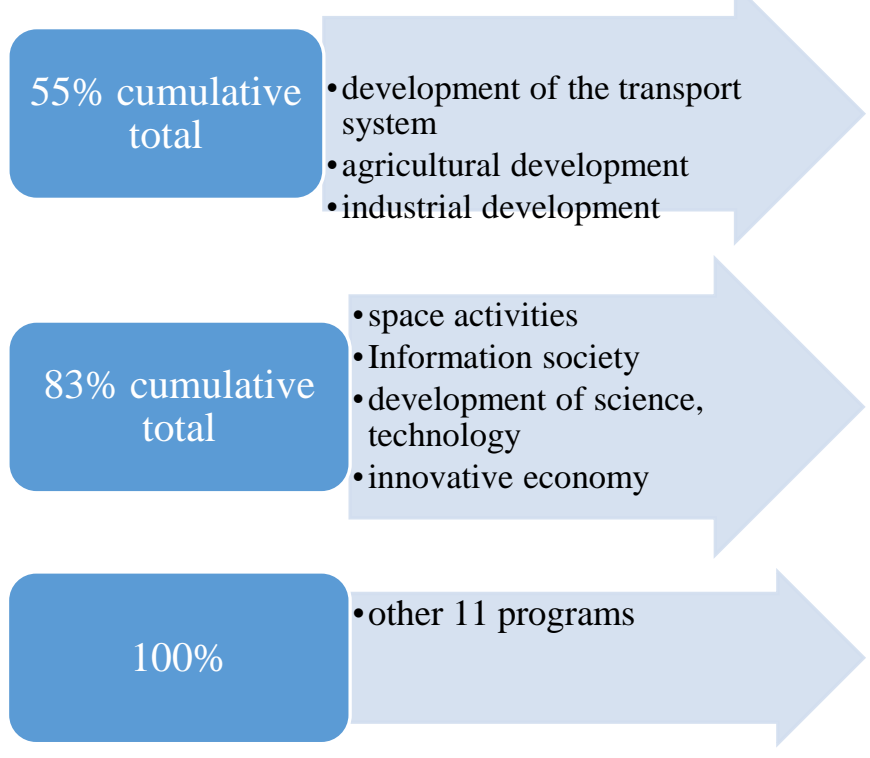

Fig.8. Distribution of state programs in the direction of innovative development by the amount of funding accumulated

As you know, one of the latest tools for implementing state policy are national projects. In total, it is planned to allocate more than 27.8 trillion rubles for 12 projects that have different directions, affecting not only economic development, but also social development. As can be seen from Table 2, most of the expenditures are directed to the development of infrastructure and the construction of highways, which is more than $40 \%$ of all funds provided. About $14-15 \%$ of all funds will be allocated to the directions "ecology" and "demography». Only 491.7 billion rubles are envisaged to support entrepreneurship, which is less than $2 \%$. 
TABLE I. LIST OF MAIN EXPENSES

\begin{tabular}{|c|c|c|}
\hline Name & RUB bln & Sp. Weight, \% \\
\hline $\begin{array}{c}\text { Comprehensive plan for the } \\
\text { modernization and expansion of the } \\
\text { main infrastructure }\end{array}$ & $7,087.00$ & 25.45 \\
\hline Safe and high-quality roads & $4,965.60$ & 17.83 \\
\hline Ecology & 4106.90 & 14.75 \\
\hline Demography & $3,976.60$ & 14.28 \\
\hline Digital economy & 1985.30 & 7.13 \\
\hline Health care & $1,535.70$ & 5.52 \\
\hline Housing and urban environment & $1,073.50$ & 3.86 \\
\hline $\begin{array}{c}\text { International cooperation and } \\
\text { export }\end{array}$ & 907.90 & 3.26 \\
\hline Education & 886.70 & 3.18 \\
\hline The science & 631.20 & 2.27 \\
\hline $\begin{array}{c}\text { Small and medium-sized businesses } \\
\text { and support for individual } \\
\text { entrepreneurial initiative }\end{array}$ & 491.70 & 1.77 \\
\hline Culture & & \\
\hline $\begin{array}{c}\text { Labor productivity and employment } \\
\text { support }\end{array}$ & 67.90 & 0.46 \\
\hline TOTAL & $27,843.50$ & 100,00 \\
\hline
\end{tabular}

Most of the funds for financing national projects will be allocated from the federal budget. The constituent entities of the Russian Federation should also participate in the implementation of projects, while their share is quite stable. It should be noted that no economic development is possible without off-budget sources.

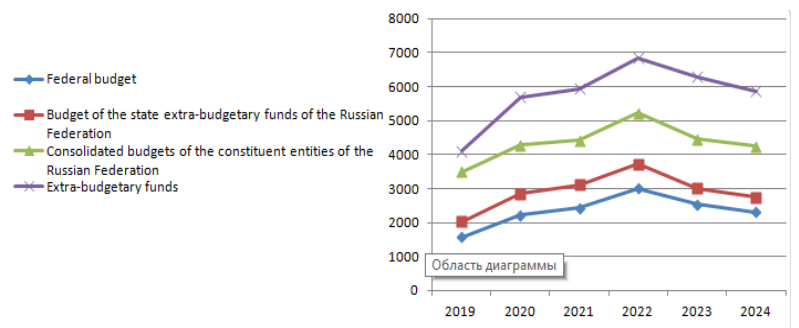

Fig.9. Amount of financial support for national projects, billion rubles.

Let us dwell on the small business support project in more detail. In total, over the period of the project implementation, 481.5 billion should be allocated for the implementation of measures, of which 416.2 billion rubles from the federal budget. 261.8 billion rubles are provided for expanding the access of SMEs to financial resources, for acceleration - 167.9 billion rubles, for popularization -8.5 billion rubles, for supporting farmers 40.8 billion rubles. Because of the project, the number of people employed in the system of small and mediumsized businesses should reach 25 million, new SMEs - 62 thousand by 2024 , and the share of SMEs in GDP - $32.5 \%$.

Let us consider what the specific areas are of support for small and medium-sized businesses within the framework of this project. Providing a soft loan at a rate of $8.5 \%$ per annum, while the state compensates banks for lost profits. Entrepreneurs related to SMEs in agriculture, manufacturing, construction, tourism, communications, education, science, healthcare, trade and other areas are eligible for this support. Funds from a soft loan can be used to replenish current assets up to a maximum of 500 million rubles for a period of up to 3 years, or for investment purposes. Such as the purchase of equipment, premises, reconstruction of production for a period of up to 10 years for an amount of up to 2 billion rubles. It is also possible for SMEs to provide microloans of up to 5 million rubles for a period of up to 3 years. The interest rate varies from 3.25 to $16.25 \%$ depending on the program and collateral. Various microfinance funds are being created in the constituent entities of the Russian Federation. For example, in the Krasnodar Territory, the microfinance fund developed a special Start program, according to which beginner entrepreneurs could receive up to 300 thousand rubles, while the Student program is supposed to have a preferential rate of $3.5 \%$ for 6 months.

One of the ways to develop new industrial and innovative projects is to provide ready-made infrastructure and preferential access to it. Within the framework of the national project to support small and medium-sized enterprises of the RF Ministry of Economic Development has developed a special program for the development of technology parks and industrial parks. The state will continue to subsidize their construction and modernization. By 2024, at least 129 industrial parks and technology parks are planned to open throughout the country. In order to support innovation, support is provided for technology parks and industrial parks. Therefore, until 2024 plans to open at least 129 objects SME infrastructure, the role of government is to construction subsidies and modernization of the fleet. Residents of techno parks are provided with privileges in taxes, rent, and product promotion. In October 2020, the amount of support for individual entrepreneurial initiatives was increased to 1 million rubles, preferential rent of business incubators, and guaranteed assistance. In May 2020, as part of anti-crisis measures, it was decided to allocate 12 billion rubles from the reserve fund of the Government of the Russian Federation to increase funding for this national project. Because of this change, the amount of subsidies for the creation and development of microfinance organizations was increased, for subsidizing the microloan rate.

In November 2020, as part of measures to support businesses during the coronavirus pandemic, VEB.RF issued guarantees to banks for 500 billion rubles for issuing soft loans to entrepreneurs. Entrepreneurs received support, which saved 5 million people. VEB issued in favor of commercial banks on soft loans to entrepreneurs with a zero or reduced rate for 500 billion rubles. One of the important areas of support for employment in a pandemic is preferential loans at $2 \%$ per annum until April 1, 2021 with a deferred payment until the end of December 2020, provided that 90\% of the staff is retained, the state will fully pay off the debt to the bank. If $80 \%$ of the state is retained, then the state will pay off $50 \%$ of the debt and interest on it. The grace period may also be extended. This measure, in our opinion, is very important both for entrepreneurs themselves and for employees. Because the period of the pandemic has dragged on, its end is unknown, it is necessary to extend the program, increase the amount of funding.

One area of support for small and medium-sized businesses is tax holidays. So, in November 2020, it was decided to extend tax holidays for enterprises operating in the fields of culture, tourism, hotel business, catering, entertainment and sports, as well as in the field of organizing conferences and exhibitions.

According to the Ministry of Economic Development of Russia, since the beginning of 2020, more than 774 billion rubles have been issued under loan agreements with a rate of 
$8.5 \%$ per annum. Due to the pandemic, certain requirements were not taken into account when issuing loans - the absence of tax arrears and wage arrears. In connection with this and the changes, the volume of loans issued amounted to about 900 billion rubles. In addition, viewed in the z possibility of reducing marginal subsidized rate from 8.5 to $7 \%$. We believe this innovation should contribute to the development of economic development.

Russian regions also participate in national projects. Therefore, for example, in the Pskov region to 100 $\mathrm{m} 1 \mathrm{n}$ rubles for granting soft loans to SMEs, in order to avoid a wave of bankruptcies and create new companies. In addition to loans, industrial mortgages are provided. The Regional Fund for Guarantees and Entrepreneurship Development annually provides microcredits to SMEs at a preferential rate of $6 \%$ for a loan term of up to a year and $10 \%$ if the term is longer. The maximum loan amount can be 5 million rubles; the maximum term is three years. Most of the funds will be provided from the federal budget - 290 million rubles until 2024, and from the consolidated budget of the region - 2, 8 million rubles. In general, 390 million rubles will be allocated to support entrepreneurship in 2020, in particular, topopularize entrepreneurship, to launch programs to accelerate SMEs, including conducting training seminars and forums. In addition, part of the funds will be directed to support entrepreneurs working in the agro-industrial complex.

In the Kaluga Region, during the pandemic, more than 1 billion rubles were allocated to support business, which was received by 22 thousand enterprises. Guaranteed support for SMEs in Russia made it possible to attract 14.5 billion rubles for business development in the Kaluga Region. Over 5 years, the guarantee was provided to more than 460 transactions of small enterprises, guarantee support - about 7 billion rubles, preferential lending made it possible to attract funds in the implementation of projects for 14.5 billion rubles.

One of the areas of support for SMEs is to support farmers and agricultural producers. The size of the allocated budget for the creation of a system of support for farmers and the development of rural cooperation in the constituent entities in 2019 was planned in the amount of 7.373 billion rubles, in 2020 - 1.836, in 2021 - 4.608, in 2022 - 5.914, in $2023-8.514$, in $2024-9.123$ billion rubles. The number of people involved in SMEs operating in the field of agriculture, including through state support funds, should increase from 18,216 thousand in 2019 to 30,930 in 2024. In the Altai Territory, more than 16 million rubles were allocated to support four farms. At the same time, membership in an agricultural cooperative is considered a prerequisite for receiving support. The allocated funds are planned to be used for the purchase of highly productive livestock, forage harvesting equipment, equipment for the transportation and processing of milk. Sverdlovsk farmers received grants of up to 6 million rubles for the development of the economy. At the same time, all recipients of support measures must create additional jobs. Grant, "Agrostartap» of up to six million rubles for the development of peasant farming will receive ten farmers for breeding cattle for other types of activity - up to four million rubles. Grants are allocated subject to cofinancing: up to $90 \%$ of the required amount provided by the Ministry of agro industrial complex (AIC) of the Sverdlovsk region and at least $10 \%$ of the farmer must make himself. All recipients of support measures must create additional jobs.

Thus, the analysis showed that a large part of government spending is distributed through government programs and national projects. More than $75 \%$ of federal budget expenditures are the part of the program. In connection with the implementation of the project principle, there will also be an increase in expenditures in the form of federal and national projects. Most of the program expenditures are programs in the field of the New Quality of Life, which are mostly socially oriented. Innovative programs are unbalanced; three programs make up more than half of all expenses, while they are aimed at the development of transport, agriculture and industry. The share of programs in the field of science, technology, innovative development is significantly lower.

Correlation-regression analysis showed the relationship between GDP and government spending under government programs. However, if we analyze the example of a specific program and indicators that characterize the development of this sector, the connection weakens and the model in only half of the observation cases describes the dependence. Based on this, we can conclude about the low efficiency of budget expenditures, insufficient transparency in achieving target indicators, as well as the introduction of general indicators as indicators that do not take into account the specifics of the program, which can be achieved within the framework of other programs and expenditures.

Have the sense that there is no clear system for assessing the effectiveness of expenses incurred, which does not allow for objective conclusions. It is possible to note the fact that large budget expenditures have been implemented, without the fact of assessing their effectiveness. It can also be concluded that it does not matter what instrument the spending of funds takes place - the federal target program, the state program, the federal or national project, the state's resources are spent inefficiently.

\section{CONCLUSION}

We consider it important to include in the list of programs those that meet the main goal, in particular, innovative development. In addition, activities should be correlated with the purpose of the program, and not solve various organizational, methodological issues. And the tasks related to methodological support, program management, as well as research support should be solved at the expense of other programs related to improving public administration and not inflate programs with non-core activities, taking significant financial resources.

Have the sense that State programs can contribute to the innovation-driven growth of the country, but on the basis to a careful selection of subprograms and activities, it is competent to determine the target level of indicators.

\section{REFERENCES}

[1] V.E. Zaitsev, State programs of the Russian Federation and the Republic of Korea: comparative analysis, Bulletin of the Institute of Economics of the Russian Academy of Science, 5,2018, $187 \mathrm{p}$

[2] A.M. Kalinin, "Evolution of instruments of Government support for industry in the Russian Federation: from Federal Target Program to G State Program", Prediction problem, 2018, 1 (166), pp. 38-47.

[3] G.I. Idrisov, S.G. Sinelnikov-Murylev, "Budgetary Policies and Economic Growth", Economic matters. 2013, 8, pp. 35-59

[4] F. Forte, C. Magazzino, "Optimal Size of Government and Economic Growth in Eu-27" Electronic resource. URL: https://mpra.ub.uni- 
muenchen.de/26669/1/MPRA_paper_26669.pdf/_accessed 03.11.2020)

[5] A. Illarionova, N. Pivovarova, "Size of the Government and Economic growth", Economic matters, 2002, 9, pp. 18-45.

[6] A. A. Batista, E. M. Ribeiro, N. M. Gomes \& A. N. Paula, The financing of territorial development in jequitinhonha mineiro between 2003-2015, Journal of Economics and Rural Sociology, 59(2), e215057. https://doi.org/10.1590/1806-9479.2021.215057/ (accessed 03.10.2020).

[7] Portal of the State Program of the Russian Federation. [Electronic resource] URL: https://programs.gov.ru//(accessed 03.10.2020).

[8] Official data of the Federal Treasury of the Russian Federation [Electronic resource]. URL: http://datamarts.roskazna.ru/(accessed 03.10.2020).

[9] Official website of the Ministry of Finance of the Russian Federation [Electronic resource]. URL:www.minfin.ru/(accessed 03.10.2020).

[10] Official website of the Federal State Statistics Service [Electronic resource]. URL:https://www.gks.ru/(accessed 03.10.2020).

[11] Imam Ibrahim Maryam, Bintu Mustapha, "Determinants of Small and Medium Enterprises Performance in Nigeria: The Role of Government Support Policy". International Journal of Business and Economics Research. Volume 8, Issue 2, April, 2019, p. 41-49

[12] M. W. Staniewski, R.Nowacki, K. Awruk, "Entrepreneurship and innovativeness of small and medium sized construction enterprises". International Entrepreneurship and Management Journal, (2016) pp. 117. DOI: http://doi.org/10.1007/s11365-016-0385-8

[13] O.V. Voronkova, A.A. Kurochkina, I.P. Firova, T.V. Bikezina. Current Trends in the Development of Small and Medium-Sized Enterprises and Individual Entrepreneurship in the Russian Federation. Revista Espacios, 2018, Volume 39, 13 p. URL: http://www.revistaespacios.com/a18v39n41/a18v39n41p13.pdf/ (accessed 03.10.2020).

[14] V. Barinova and Zemtsov, Stepan and Tsareva, Yulia, "Government Support of Small and Medium Sized Entrepreneurship in Russia (September 5, 2019). Russian Economy in 2018. Trends and Outlooks (Issue 40). Moscow. IEP. 2019, pp. 543-563. URL: https://ssrn.com/abstract=3449232 http://dx.doi.org/10.2139/ssrn.3449232/(accessed 03.10.2020)

[15] V.Botrić and L.Božić, "Access to Finance: Innovative Firms' Perceptions in PostTransition EU Members", EaM: Ekonomie a Management, 20(1), 2017. pp.129-143.

[16] V.V. Kookueva, "Trends of financing sustainable development of rural areas in Russia", Life Science Journal, 2014, 11, p. 310-314. 